\title{
Synthesis and Characterization of Hydroxyapatite Powder by Sol-Gel Method for Biomedical Application
}

\author{
Khelendra Agrawal*, Gurbhinder Singh, Devendra Puri, Satya Prakash \\ Metallurgical and Materials Engineering Department, Indian Institute of Technology \\ Roorkee- 247667, India \\ *Corresponding Author: khelendraagrawal@gmail.com
}

\begin{abstract}
Hydroxyapatite (HA) is effectively used as a bioimplant material because it closely resembles bone apatite and exhibits good biocompatibility. This paper describe synthesis technique of HA powder by sol-gel method. The product was sintered twice at two different temperatures $400^{\circ} \mathrm{C}$ to $750^{\circ} \mathrm{C}$ to improve its crystallinity. The final powder sintered at two temperatures was characterized by X-ray analysis, Scanning electron microscopy (SEM) and Fourier Transform Infrared Spectroscopy (FT-IR) to reveal its phase content, morphology and types of bond present within it. Thermal analysis (TG-DTA) was carried out to investigate the thermal stability of the powder.
\end{abstract}

Keywords: Hydroxyapatite, bioimplant, sol-gel, X-ray diffraction, FT-IR, TG-DTA

\section{INTRODUCTION}

Hydroxyapatite $\left(\mathrm{Ca}_{10}\left(\mathrm{PO}_{4}\right)_{6}(\mathrm{OH})_{2}, \mathrm{HA}\right)$ is an important inorganic biomaterial which has attracted the attention of researchers related to biomaterials field in recent years. Due to its chemical and structural similarity with the mineral phase of bone and teeth, HA is widely used for hard tissues repair. As a result, this inorganic phosphate has been studied extensively for medical applications in the form of powders, composites or even coatings [1-11]. It is also observed that dense sintered HA has many bone replacement applications and is used for repairing bone defects in dental and orthopedic sites, immediate tooth replacement, augmentation of alveolar ridges, pulp capping material and maxillo facial reconstruction, etc [12]. For substituting or repairing the bone, the designed material must has the ability to create a bond with the host living bone [13]. Hence, it is always desirable to include a high degree of crystallinity and chemical stability among the desirable properties of an ideal hydroxyapatite $[14,15]$. Furthermore, HA has also been studied for other non-medical 
applications, for example, as packing media for column chromatography, gas sensors, catalysts, etc. $[2,16]$. However, poor mechanical properties, e.g. low strength and toughness, restrict monolithic HA applications to those that require little or no load-bearing parts [17]. Due to its diverse applications, the materials properties accordingly need to be tailored for real world application. Hence researchers have tried to customize its properties such as bioactivity, mechanical strength, solubility and sinterability by controlling its composition, morphology and particle size $[9,10]$.

The chemical, structural and morphological properties of synthetic HA can be modulated by varying the method and the conditions of synthesis. Classical methods for HA powder synthesis include direct precipitation, hydrothermal techniques, hydrolysis of other calcium phosphates, as well as solid-state reactions $[18,19]$ and mechano-chemical methods [20, 21]. One of the most widely used methods is wet precipitation, where chemical reactions take place between calcium and phosphorus ions under a controlled $\mathrm{pH}$ and temperature of the solution. The precipitated powder is typically calcined at $400-600^{\circ} \mathrm{C}$ or even at higher temperature in order to obtain a stoichiometric, apatitic structure. In some cases, a wellcrystallized HA phase was only developed while approaching a sintering temperature of $1200^{\circ} \mathrm{C}$. However, fast precipitation during phosphate solution titration (to calcium solution) leads to chemical in homogeneity in the final product. Slow titration and diluted solutions must be used to improve chemical homogeneity and stoichiometry of the resulting HA. Careful control of the solution condition is critical in the wet precipitation. Otherwise, a decrease of solution $\mathrm{pH}$ below about 9 could lead to the formation of Ca-deficient HA structure [17].

Most of the wet methods are time-consuming because the formation of HA phase and the rinsing of unnecessary anions all take time. A method involving non-aqueous systems to synthesize HA has also been reported [22], in which a viscous solution was first obtained by hydrolysis and oxidation of a mixed acetone solution of calcium nitrate $\left(\mathrm{Ca}\left(\mathrm{NO}_{3}\right)_{2} \cdot 4 \mathrm{H}_{2} \mathrm{O}\right)$ and phenydichlorophosphine $\left(\mathrm{C}_{6} \mathrm{H}_{5} \mathrm{PCl}_{2}\right)$. After the viscous solution was dried and calcined at above $700^{\circ} \mathrm{C}$, HA Powder was obtained. However, the method is usually not so simple due to the need of hydrolysis and oxidation steps.

Sol-gel technique have attracted much attention recently $[5,6,9-11]$ due to its well-known inherent advantages to generate glass, glass-ceramic and ceramics powders. These include homogeneous molecular mixing, low processing temperature, the ability to generate sized particles, the tremendous flexibility to generate nanocrystalline powders, bulk amorphous monolithic solids and thin films [23]. The sol-gel process is easily applicable to surface coating and it allows the preparation of high-quality HA thin films on metal substrates [7-10]. Thus, the sol-gel process can be usefully utilized to synthesize both HA powders and HA films under significantly mild conditions. The versatility of the sol-gel method opens a great opportunity to form thin film coatings in a rather simple process, an alternative to thermal spraying which is currently widely used for biomedical applications [24, 25].

Accordingly, the objective of the present work is to synthesis of HA powder from sol-gel method and carried out its characterization. 


\section{EXPERIMENTAL PROCEDURE}

\subsection{Powder Preparation}

In this method two different chemical reagents (precursors) were used. At first phosphoric pentoxide $\mathrm{P}_{2} \mathrm{O}_{5}$ (Merck) was dissolved in absolute ethanol (Fisher Scientific) to form a 0.5 $\mathrm{mol} / \mathrm{l}$ solution and secondly calcium nitrate tetrahydrate $\mathrm{Ca}\left(\mathrm{NO}_{3}\right)_{2} \cdot 4 \mathrm{H}_{2} \mathrm{O}($ Merck) was also dissolved in ethanol to form $1.67 \mathrm{~mol} / 1$ solution. After this both the solutions were mixed to obtain the desired $\mathrm{Ca} / \mathrm{P}$ molar ratio of 1.67 . It was reported in the previous literature [26] that sequence of the dissolution of the reagents did not affect the process, but rapid addition of any one reagent to another reagent can cause precipitation. Hence the solution was stirred slowly for 10 to $15 \mathrm{~h}$ until the formation of a gel. Further the gel was dried in an electric oven at $80^{\circ} \mathrm{C}$ in air for $20 \mathrm{~h}$, followed by two stage heat treatment in stagnant air starting from $400^{\circ} \mathrm{C}$ to $750^{\circ} \mathrm{C}$ for $8 \mathrm{~h}$. The whole procedure was as shown in the flow diagram given below.

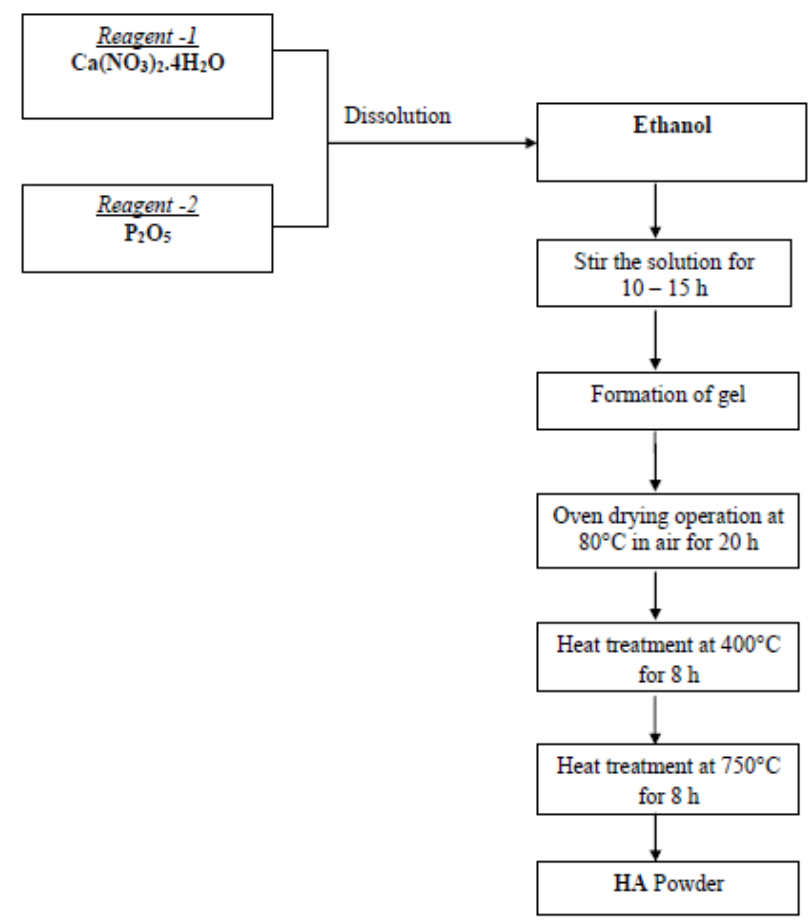

Fig. 1. Schematic flow process chart for the synthesis of $\mathrm{HA}$ by the use of $\mathrm{Ca}\left(\mathrm{NO}_{3}\right)_{2} \cdot 4 \mathrm{H}_{2} \mathrm{O}$ and $\mathrm{P}_{2} \mathrm{O}_{5}$

\subsection{Powder Characterization}

The crystallographic phases of HA powder was determined by X-ray diffractometer (XRD) using a (Bruker D8 Advance, Germany) diffractometer in reflection mode with $\mathrm{Cu} \mathrm{K} \alpha$ $(\lambda=1.5405 \AA)$ radiation. The data were collected in the $2 \Theta$ range from $15^{\circ}$ to $80^{\circ}$ with a scanning speed of $1.5^{\circ} / \mathrm{min}$. The presence of functional groups was confirmed by using Fourier transform infrared spectroscopy (Thermo NICOLET 5700, FTIR). The FT-IR spectra 
were obtained over the region $400-4,000 \mathrm{~cm}^{-1}$ using $\mathrm{KBr}$ pellet technique. The resolution of spectrometer was $4 \mathrm{~cm}^{-1}$. The surface morphology and microstructural features of the synthesized HA powder with elemental composition was studied and evaluated by Field Emission Scanning Electron Microscope (FE-SEM) (FEI Quanta 200F, Czech Republic) fitted with energy dispersive X-ray (EDAX). Thermo gravimetric analysis (TGA) equipped with differential thermal analysis (DTA) of the powder was done with (Perkin Elmer Pyris Diamond) thermal analyzer in air atmosphere at a heating rate of $10^{\circ} \mathrm{C} / \mathrm{min}$ up to $1200^{\circ} \mathrm{C}$.

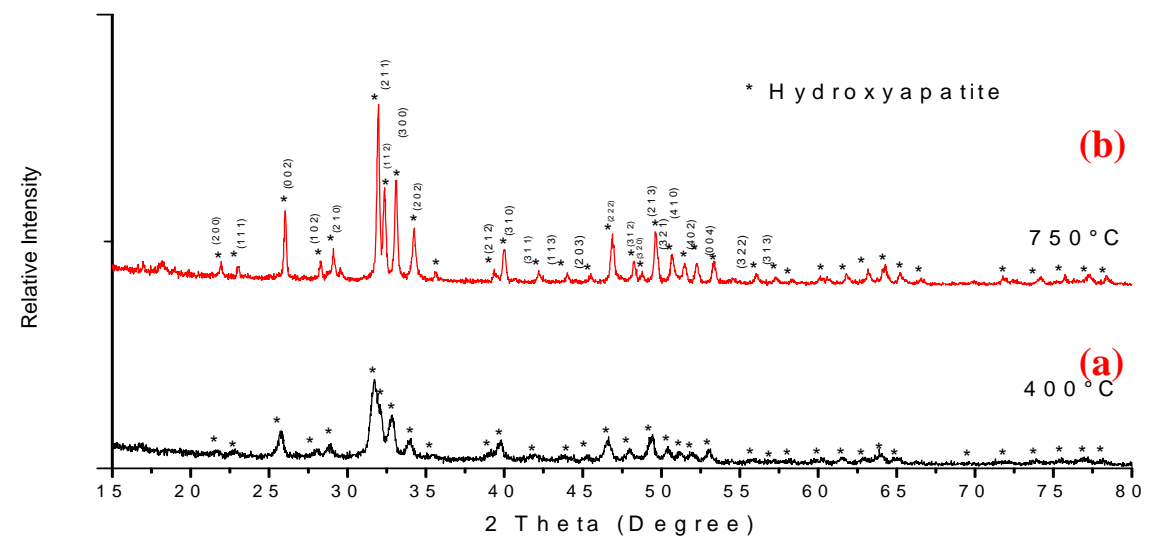

Fig. 2. XRD patterns of the HA powder sintered at (a) $400^{\circ} \mathrm{C}$ and (b) $750^{\circ} \mathrm{C}$.

\section{RESULTS AND DISCUSSION}

\subsection{X- ray Diffraction Analysis}

An XRD pattern of a sol-gel prepared powder that was sintered at $400^{\circ} \mathrm{C}$ and $750^{\circ} \mathrm{C}$ is shown in Fig. 2 (a) and (b). It can be observed from both figures that the XRD analysis of the powders synthesized at $400^{\circ} \mathrm{C}$ and $750^{\circ} \mathrm{C}$ resembles with the standard HA powder pattern. The effect of sintering temperature on the formation of HA can be seen in Fig. 2 (a) and (b). The sintering temperature plays an important role on the formation of HA. The samples heated at $400^{\circ} \mathrm{C}$ show broad peaks indicating the formation crystalline phase, which was increased with the increase of sintering temperature. As the sintering temperature is increased from $400^{\circ} \mathrm{C}$ to $750^{\circ} \mathrm{C}$, several peaks of XRD pattern which belongs to the HA powder become more distinct and, also the widths of the peaks become more narrow, which suggests that there is an increase in the crystallinity of powder. It can also be seen that no additional crystalline phases is present besides $\mathrm{HA}$ at $750^{\circ} \mathrm{C}$.

\subsection{FT-IR Analysis}

The FT-IR spectra of HA samples at $400^{\circ} \mathrm{C}$ and $750^{\circ} \mathrm{C}$ are shown in Fig. 3 (a) and (b). From the graph it is indicated that there is a broad envelop between $3825 \mathrm{~cm}^{-1}$ and $2550.16 \mathrm{~cm}^{-1}$. The O-H stretching bond is shown at $3580.74 \mathrm{~cm}^{-1}$ in sample (a) and $3575.02 \mathrm{~cm}^{-1}$ in sample 
(b), which confirms the presence of hydroxyapatite powder [7, 27]. A weak band of $\mathrm{CO}_{3}{ }^{2-}$ was detected in the region around $1567.78 \mathrm{~cm}^{-1}$ in sample (a) and $1554.23 \mathrm{~cm}^{-1}, 834.65 \mathrm{~cm}^{-1}$ in sample (b). This band indicates or confirms the minor amount of carbonate substitution. Initially at lower sintering temperature these peaks are broad but with increase of sintering temperature the peaks get ill-defined due to elimination of $\mathrm{CO}_{3}{ }^{2-}$. The peak at $976.89 \mathrm{~cm}^{-1}$ corresponds to symmetric stretching mode of $\mathrm{PO}_{4}{ }^{3-}$. The peaks at $623.02 \mathrm{~cm}^{-1}$ and $560 \mathrm{~cm}^{-1}$ for sample at $400^{\circ} \mathrm{C}$ and $589.7 \mathrm{~cm}^{-1}$ for sample at $700^{\circ} \mathrm{C}$ indicate the bending mode of $\mathrm{PO}_{4}{ }^{3-}$. The large separation of these bands indicates the presence of crystalline phase [28, 29].

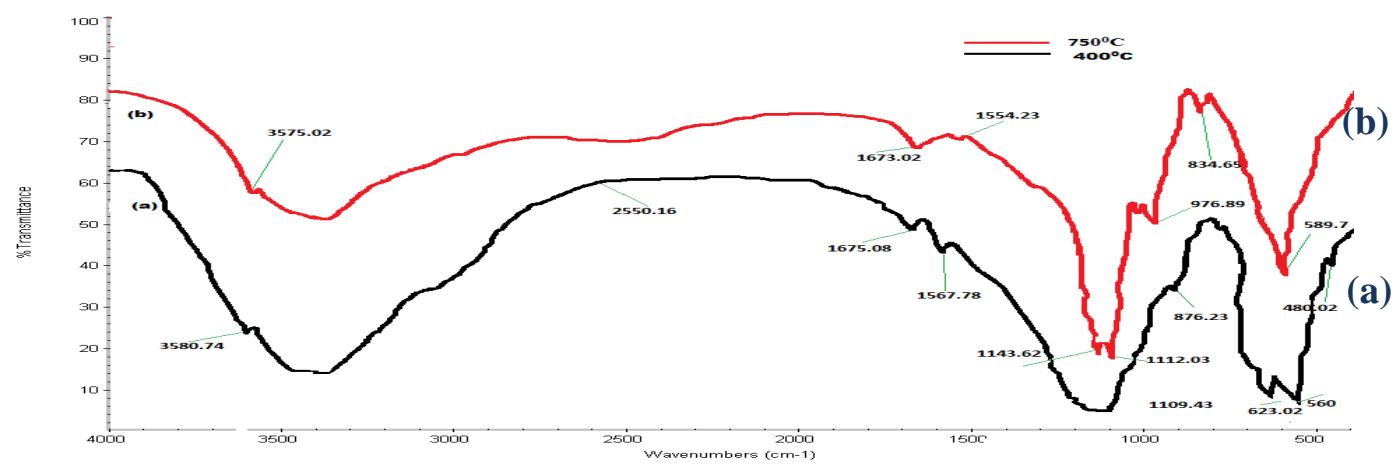

Fig. 3. FT-IR patterns of the HA powder sintered at (a) $400^{\circ} \mathrm{C}$ and (b) $750^{\circ} \mathrm{C}$.

\subsection{DTA-TG Analysis}

TG (Fig.4.) analysis shows that there is weight loss of around $12 \%$ up to temperature $220^{\circ} \mathrm{C}$ and approximately $40 \%$ in the range $220^{\circ} \mathrm{C}$ to $350^{\circ} \mathrm{C}$. This major loss confirmed the formation of $\mathrm{HA}$, similarly about $5 \%$ wt. loss was observed up to $600^{\circ} \mathrm{C}$. Beyond $600^{\circ} \mathrm{C}$ to $1200^{\circ} \mathrm{C}$ no significant wt. loss was observed. Almost stable curve was noticed within this temperature range, which indicates thermal stability of HA powder.

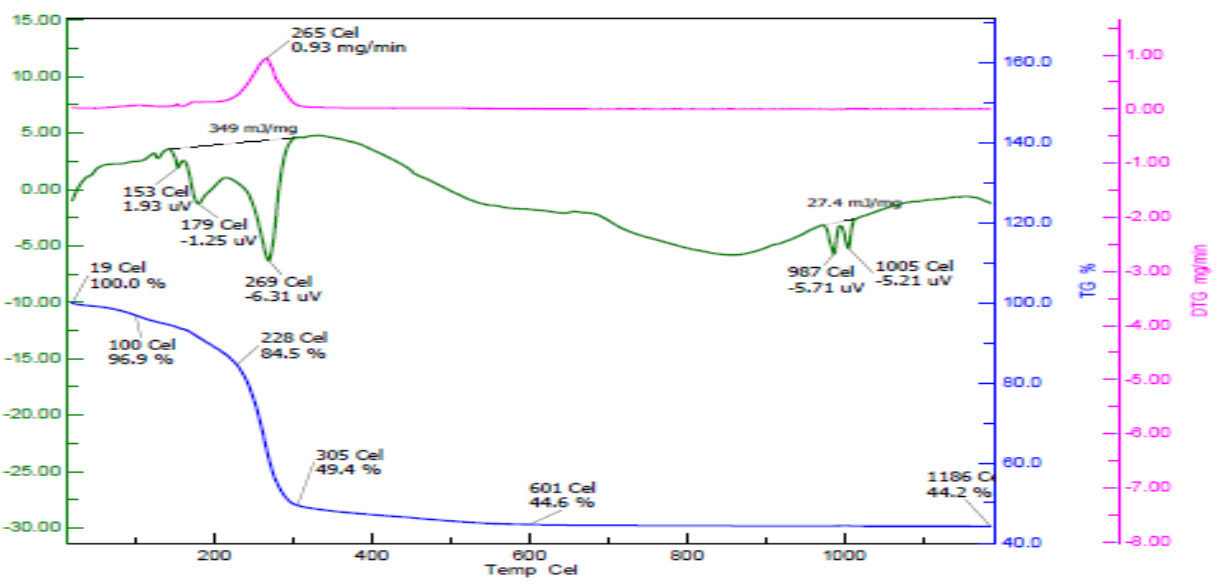

Fig. 4. TG-DTA patterns of the sintered powder 
In DTA curve initially there are series of small curves occur which is followed by a broad curve between approx. $\left(215^{\circ} \mathrm{C}\right.$ to $\left.330^{\circ} \mathrm{C}\right)$. This is occurring because evaporation of water in calcium nitrate tetrahydrate $\mathrm{Ca}\left(\mathrm{NO}_{3}\right)_{2} \cdot 4 \mathrm{H}_{2} \mathrm{O}$ happens. Similarly the other endothermic peaks in the curve related to the removal or addition of other groups during the synthesis of HA powder. However in the starting at $200^{\circ} \mathrm{C}$ a sharp exotherm indicates the crystallization of HA.

\subsection{SEM- Analysis}
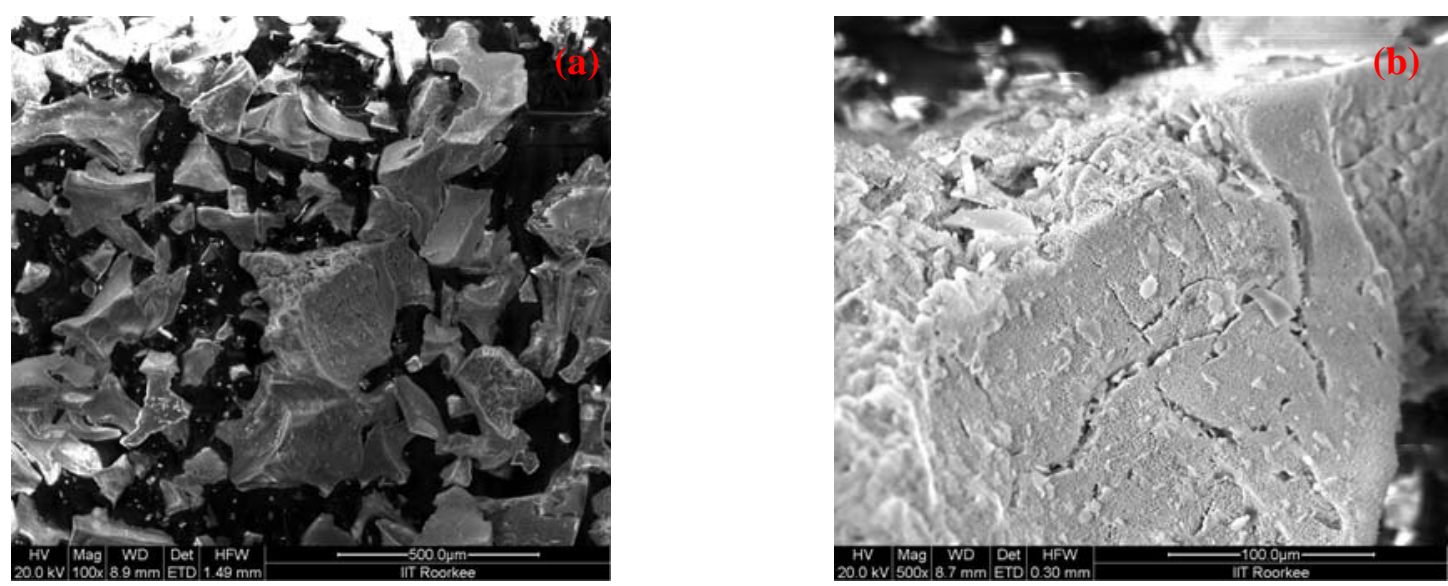

Fig. 5. SEM micrographs of synthesized HA powder sintered at $750^{\circ} \mathrm{C}$ temperature for $8 \mathrm{hr}$ at (a) $100 \mathrm{X}$ (b) $500 \mathrm{X}$

The above Figure 5 shows the SEM images of the synthesized powder obtained after heattreatment at $750^{\circ} \mathrm{C}$ for $8 \mathrm{~h}$ in stagnant air. The powder appears to be of crushed angular shape when observed at 100X in Figure 5(a). Figure 5(b) which was taken at higher magnification reveals single particle of HA is made of agglomeration of nano sized grains. These grains may be agglomerated due to the formation of the gel during the synthesis process.

\section{CONCLUSION}

This study presents an alternative method to form pure, stable, good crystalline nanosized HA powder at low temperature maximum $\left(750^{\circ} \mathrm{C}\right)$ as compared to other existing methods where temperature of treatment is more than $800^{\circ} \mathrm{C}$ to achieve all the above characteristics. Also it was observed that the crystallinity of the synthesis powder can be improved further by increasing the sintering temperature. The nanosized HA powder produced can be highly useful as a bone replacement material. 


\section{REFERENCES}

[1] W. Weng, G. Shen, G. Han, 2000, "Low temperature preparation of hydroxyapatite coatings on titanium alloy by a sol-gel route", Materials Science Letters, Vol. 19, pp. 2187- 2188.

[2] K. Cheng, W. Weng, G. Han, P. Du, G. Shen, J. Yang, J.M.F. Ferreira, 2003, "The effect of triethanolamine on the formation of sol-gel derived fluoroapatite/hydroxyapatite solid solution", Journal of Materials Chemistry and Physics, Vol. 78, pp. 767-771.

[3] R.E. Riman, W.L. Suchanek, K. Byraopa, C-W. Chen, P. Shuk, C.S. Oakes, 2002, "Solution synthesis of hydroxyapatite designer particulates", Solid State Ionics, Vol. 151, pp. 393- 402.

[4] L-Y. Huang, K-W. Xu, J. Lu, 2000, "A study of the process and kinetics of electrochemical deposition and the hydrothermal synthesis of hydroxyapatite coatings", Journal of Materials Science: Materials in Medicine, Vol. 11, pp. 667-673.

[5] W. Weng, S. Zhang, K. Cheng, H. Qu, P. Du, G. Shen, J. Yuan, G. Han, 2003, "Solgel preparation of bioactive apatite films", Surface and Coatings Technology, Vol. 167, pp. 292-296.

[6] W. Weng, G. Han, P. Du, G. Shen, 2002, "The effect of citric acid addition on the formation of sol-gel derived hydroxyapatite", Materials Chemistry and Physics, Vol. 74, pp. 92-97.

[7] D. Choi, K. Marra, P.N. Kumta, 2004, "Chemical synthesis of hydroxyapatite/poly (Ecaprolactone) composite", Materials Research Bulletin, Vol. 39, pp. 417-432.

[8] W. Weng, J.L. Baptista, 1998, "Alkoxide route for preparing hydroxyapatite and its coatings", Biomaterials, Vol. 19, pp. 125-131.

[9] K. Cheng, W. Weng, G. Han, P. Du, G. Shen, J. Yang, J.M.F. Ferreira, 2003, "Sol-gel derived fluoridated hydroxyapatite films", Materials Research Bulletin, Vol. 38, pp. 89-97.

[10] K. Cheng, G. Shen, W. Weng, G. Han, J.M.F. Ferreira, J. Yang, 2001, "Synthesis of hydroxyapatite /fluoroapatite solid solution by a sol-gel method", Materials Letters, Vol. 51, pp. 37- 41.

[11] W. Weng, G. Han, P. Du, G. Shen, J. Yang, 2002, "The effect of citric acid addition on sol-gel preparation of apatite films", Materials Chemistry and Physics, Vol. 77, pp. 578-582.

[12] V. Shiny, P. Ramesh, M.C. Sunny, H.K. Varma, 2000, "Extrusion of hydroxyapatite to clinically significant shapes", Materials Letters, Vol. 46, pp. 142-146.

[13] T. Kokubo, H.M. Kim, M. Kawashita, 2003, "Novel bioactive materials with different mechanical properties", Biomaterials, Vol. 24, pp. 2161-2175.

[14] L.J. Jha, S.M. Best, J.C. Knoles, I. Rehman, J.D. Santos, W. Bonfield, 1997, "Preparation and characterization of fluoride-substituted apatites", Journal of Materials Science: Materials in Medicine, Vol. 8, pp. 185-191. 
[15] Y.C. Tsui, C. Doyle, T.W. Clyne, 1998, "Plasma sprayed hydroxyapatite coatings on titanium substrates Part 1: Mechanical properties and residual stress levels", Biomaterials, Vol. 19, pp. 2015-2029.

[16] W. Weng, J.L. Baptista, 1997, "A new synthesis of hydroxyapatite", Journal of the European Ceramic Society, Vol. 17, pp. 1151-1156.

[17] Dean-Mo Liu, T. Troczynski, Wenjea J. Tseng, 2001, "Water-based sol-gel synthesis of hydroxyapatite: process development”, Biomaterials, Vol. 22, pp. 1721-1730.

[18] W. Suchanek, M. Yoshimura, 1998, "Processing and properties of hydroxyapatitebased biomaterials for use as hard tissue replacement implants", Journal of Materials Research, Vol. 13, pp. 94-117.

[19] J.C. Elliott, 1994, "Structure and Chemistry of the Apatites and Other Calcium Orthophosphates", Elsevier Science, The Netherlands

[20] M. Toriyama, A. Ravaglioli, A. Krajewski, G. Gelotti, A. Piancastelli, 1997, "Synthesis of hydroxyapatite-based powders by mechano-chemical method and their sintering", Journal of the European Ceramic Society, Vol. 16, pp. 429-436.

[21] M. Otsuka, Y. Matsuda, J. Hsu, J. Fox, W. Higuchi, 1994, "Mechanochemical synthesis of bioactive material: Effect of environmental conditions on the phase transformation of calcium phosphates during grinding”, Bio-Medical Materials and Engineering, Vol. 4, pp. 357-362.

[22] U. Partenfelder, A. Engel, C. Russel, 1993, "A pyrolytic route for the formation of hydroxyapatite/fluoroapatite solid solutions", Journal of Materials Science: Materials in Medicine, Vol. 4, pp. 292-295.

[23] C.J. Brinker, G.W. Scherer, 1990, "Sol-Gel Science”, Academic Press, Boston, pp. 787.

[24] Haddow DB, James PF, Van Noort R, 1998, "Sol-gel derived calcium phosphate coatings for biomedical applications", Journal of Sol-Gel Science and Technology, Vol. 13, pp. 261-265.

[25] Chai CS, Ben-Nissan B, Pyke S, Evans L, 1995, "Sol-gel derived hydroxyapatite coatings for biomedical applications”, Materials and Manufacturing Processes, Vol. 10, pp. 205-216.

[26] Il-Seok kim, Prashant N.Kumata, "Sol-gel synthesis and characterization of nanostructured hydroxyapatite powder", Materials science and engineering B, Vol. 111, pp. 232-236, 2004.

[27] W. Weng, J.L. Baptista, 1998, "Sol-gel derived porous hydroxyapatite coatings", Journal of materials science: materials in medicine", Vol. 9, pp. 159-163.

[28] LeGeros, R.Z., “Calcium Phosphate in Oral Biology and Medicine”, Karger: Basel, 1991.

[29] Tas, A.C, 2000, "Synthesis of biomimetic Ca hydroxyapatite powders at $37^{\circ} \mathrm{C}$ in synthetic body fluids", Biomaterials, Vol. 21, pp. 1429. 